\title{
A paradigm shift in medicine: autologous fecal microbiota transplantation (FMT), precision nutrition and promotion of proactivity in patients
}

\author{
Jesús Álvarez-Herms ${ }^{1-3}$, Iñaki Odriozola-García ${ }^{2,4}$ and Adrian Odriozola-Martínez ${ }^{1-3 *}$ \\ ${ }^{1}$ Sport Genomics Research Group, Department of Genetics, Physical Anthropology and Animal Physiology, Faculty of Science and Technology, University of the \\ Basque Country (UPV/EHU), Leioa, Spain \\ ${ }^{2}$ KDNA Genomics ${ }^{\circledR}$, University of the Basque Country UPV/EHU, Joxe Mari Korta Research Center, Donostia-San Sebastián, Spain \\ ${ }^{3}$ Phymo ${ }^{\circledR}$ Lab, Physiology, and Molecular laboratory. Spain \\ ${ }^{4}$ Health Department of Basque Government. Donostia-San Sebastián, Spain
}

\begin{abstract}
A theoretical waste, with enormous beneficial potential
Fecal Microbiome Transplants (FMT), represent a paradigm shift in human medicine. Not in nature, where many animals such as Coleoptera, Lagomorphs, Primates, and Canis practice coprophagy as natural probiotics and nutrient source, and as extra digestion to harvest partially digested compounds [1]. Feces, traditionally considered only as waste, actually are composed by water (75\% at a median $\mathrm{pH}$ of 6.7$)$, by a diverse community of Bacteria, Fungi, Archaea, helminths, and Virus (25 - $54 \%$ of dry solids), and by undigested carbohydrate, fiber, protein, fat, and inorganic components from the diet, overall with enormous potential in health benefits [2,3].
\end{abstract}

\section{Fecal Microbiota Transplants, Disruption factors, and Dysbiosis}

The concept behind Fecal microbiota transplantation is that many factors are disrupting the healthy balance of our microbiota, such as unhealthy nutrition [4], sedentarism [5], antibiotics [6], pathogens [7], and physical and mental stress [8], and that we can restore it directly introducing a healthy fecal microbiota sample [9-11].

These disruptions produce microbiota dysbiosis [12], meaning a disturbance in the quantitative and qualitative composition of the microbiota, which impairs its functionality regarding phenotypes such as regulation of inflammation and metabolism [13], intestinal permeability [14], immune system [15], B and K group vitamins [16], and neurotransmitters [17]. Similarly, this dysbiosis decreases our allostatic capacity in front of disruption factors, and overall provoking the following negative cycle (Figure 1).

Therefore, theoretical wastes represent an excellent natural tool for the treatment of diseases, as it has been widely proven in the case of recurrent Clostridioides difficile infection [10], inflammatory bowel disease (especially in ulcerative colitis) [18], and recently in systemic sclerosis [11]. FMT has shown overall high efficacy and low adverse side effects $[10,11,15]$. In the present, it is being explored as a therapy for other more complex conditions associated to gut microbiota dysbiosis such as obesity [19], diabetes [20], autism [21], psoriasis [22], kidney stones [23] or even to more severe symptomatology in COVID-19 infection [24].

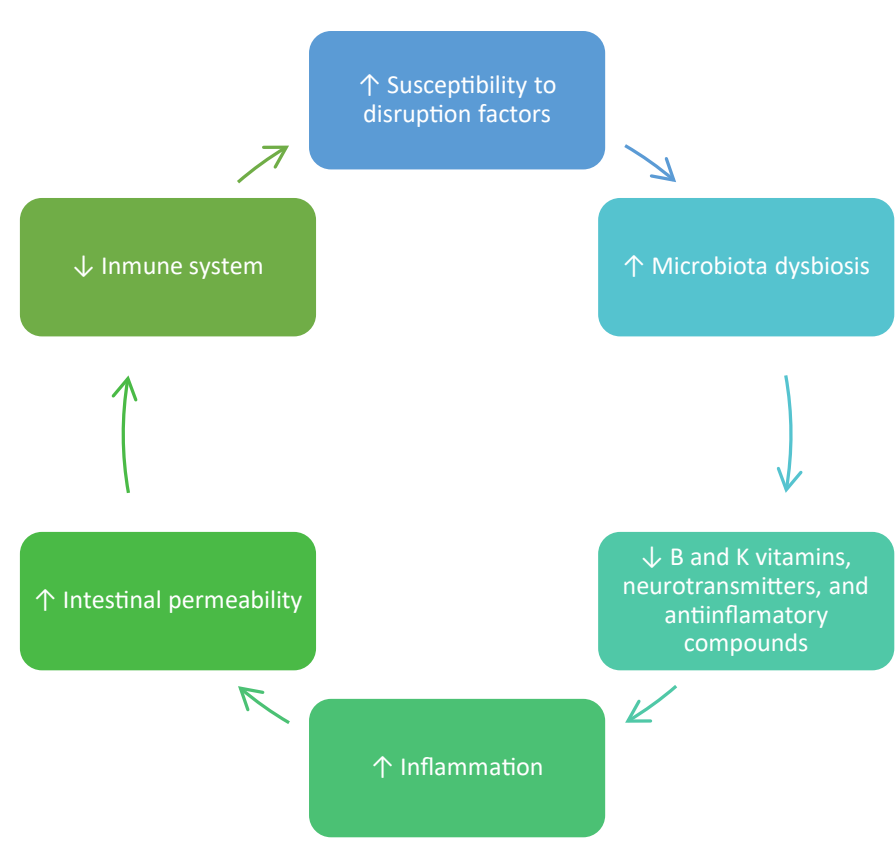

Figure 1. Negative cycle in microbiota dysbiosis

Key aspects in the improvement of Fecal Microbiota transplants

Overall, FMT is a powerful tool to interrupt the negative cycle regarding microbiota dysbiosis associated to different diseases, turning to a positive cycle. Although its enormous potential, the widespread dissemination of microbiota transplantation requires to overcome limitations in aspects such as the knowledge of case-effect relationships

*Correspondence to: Adrian Odriozola Martínez, Sport Genomics Research Group, Department of Genetics, Physical Anthropology and Animal Physiology, Faculty of Science and Technology, University of the Basque Country (UPV/ EHU), Leioa, Spain, E-mail: adrian.odriozola@ehu.eus

Key words: autologous, fecal microbiota transplantation, dysbiosis, precision nutrition, disruption factors

Received: July 25, 2020; Accepted: July 28, 2020; Published: July 31, 2020 
Table 1. Main research areas and key points in Fecal Microbiota Transplants

\begin{tabular}{|l|l|}
\hline Research area & Key point \\
\hline Cause-effect relationships & design-build-test-learn (DBTL) cycle [25]. \\
\hline Super-stool donor recruitment & selection and screening [26]. \\
\hline Samples management & $\begin{array}{l}\text { standardization of collection, preparation } \\
\text { and storage of samples [27]. }\end{array}$ \\
\hline Patient management & $\begin{array}{l}\text { Updated monitoring outcomes and ethical } \\
\text { issues [27]. }\end{array}$ \\
\hline Microbiota banks & $\begin{array}{l}\text { guarantying reliable, timely and equitable } \\
\text { access to safety transplantation [27]. }\end{array}$ \\
\hline Disruption factor minimization & $\begin{array}{l}\text { reinforcing the importance of identifying } \\
\text { and minimizing exposure to them } \\
{[4,8,10,15] .}\end{array}$ \\
\hline Allostasis against disruption factors & $\begin{array}{l}\text { Improving microbiota by precision nutrition } \\
{[28], \text { physical activity [29], regulation }} \\
\text { of circadian rhythms [30], and stress } \\
\text { management [17]. }\end{array}$ \\
\hline Auto-FMT & $\begin{array}{l}\text { Avoiding donor availability and } \\
\text { recruitment, refuse and side effects; and } \\
\text { promoting proactive attitude in patients [31]. }\end{array}$ \\
\hline
\end{tabular}

[25], super-stool donor recruitment [26], samples management, monitoring patient evolution and microbiota banks [27], identification and minimization of disruption factors and the improvement of the homeostatic resistance to them, by integration of individualized interventions based on precision nutrition and healthy-microbiome life habits [28] (Table 1).

FMT advances should keep focused on identifying, selecting, and screening super-stool donors for the treatment of specific complex diseases, and on understanding cause-effect roles in each specific dysbiosis [25,26]. Actually, despite the exponential increase of scientific evidence regarding microbiome and FMT potential applications around a design-build-test-learn (DBTL) cycle [25], the biological mechanisms by it works in each case are far from being understood [26].

Similarly, the standardization of methodologies of collection, preparation, and storage of samples is needed, as well as the management of services and patients monitoring outcomes and ethical issues, according to the evolution of applications of microbiota transplantations [27]. All of these advances should be part of the microbiota banks, guarantying reliable, timely, and equitable access to safety transplantation [27].

On the other hand, to reinforce the FMT potential beneficial effect in health, complementary strategies are recommended, such as identifying disruption factors and decreasing the exposure to them to the minimum, recovering microbiota balance, and restoring the intestinal impermeability $[4,14]$. Conversely, the improvement of the microbiota balance by precision nutrition [28], physical activity [29], regulation of circadian rhythms [30], and stress management [17], will increase the allostasis against the disruption factors. In this context, precision nutrition refers to the one based on the previous knowledge of individual microbiome, genome, physiology, and habits. Its main aim is to determine individual nutritional requirements of prebiotics (bacterial food), probiotics (beneficial bacteria) and postbiotics (metabolites produced by bacteria), by supplements and preferentially by those naturally presented in food [31,32].

\section{Autologous vs. allogenic Fecal Microbiota Transplanta- tions: a way to promote proactive patients}

In the context of FMT, autologous Fecal Microbiota Transplantation (auto-FMT), represents a promising research area for new health- promoting applications [31,33]. Primarily, auto-FMT can be used to store an optimal state of an individual microbiota and to help to maintain or to restore it against the effect of different disruption factors. Auto-FMT has successfully been used in allogeneic hematopoietic stem cell transplantation (allo-HSCT) to restore the patient's gut microbiota after antibiotic administration of routine treatment ${ }^{31}$. Equally, autoFMT has been reported as a powerful tool to enhance caloric restriction effects on body weight and adiposity in obese mice [33].

Furthermore, in comparison with allogenic FMT, the auto-FMT shows the advantage of minimizing refuse or unexpected adverse side effects and, in consequence, the necessity of donor selection. Moreover, auto-FMT also means a simplification of screening methodologies. All of those can be especially essential features in a COVID-19 pandemic context [34].

Auto-FMT, as a concept, also implies a paradigm shift in the relationship between patient and medicine. It promotes the change from a relatively passive or expectant attitude to an active, autoresponsible one. From the position of waiting for a donor or a surgery to a proactive approach based on carrying out precision nutrition, and on acquiring healthy life habits, to improve microbiota balance. Reaching its optimal microbiota state could be suitable not only to auto-FMT but also to become in super-stool donor and help other patients in the treatment of different complex diseases.

\section{Conflict of interest}

The authors declare that there is no conflict of interest.

\section{References}

1. Payne CL, Webster TH, Hunt KD (2008) Coprophagy by the semi-habituated chimpanzees of Semliki, Uganda. Pan Afr News 15, 29-32.

2. Rose C, Parker A, Jefferson B, Cartmell E (2015) The Characterization of Feces and Urine: A Review of the Literature to Inform Advanced Treatment Technology. Crit. Rev. Environ Sci Technol 45: 1827-1879 [Crossref]

3. Vemuri R, Shankar EM, Chieppa M, Eri R, Kavanagh K (2020) Beyond Just Bacteria: Functional Biomes in the Gut Ecosystem Including Virome, Mycobiome, Archaeome and Helminths. Microorganisms 8: 483. [Crossref]

4. Rothschild D (2018) Environment dominates over host genetics in shaping human gut microbiota. Nature 555: 210-215. [Crossref]

5. Castellanos N (2020) A Critical Mutualism - Competition Interplay Underlies the Loss of Microbial Diversity in Sedentary Lifestyle. Front Microbiol 10: 3142. [Crossref]

6. Wilkins LJ, Monga M, Miller AW (2019) Defining Dysbiosis for a Cluster of Chronic Diseases. Sci Rep 9: 12918.

7. Bäumler AJ, Sperandio V (2016) Interactions between the microbiota and pathogenic bacteria in the gut. Nature 535: 85-93. [Crossref]

8. Cryan JF, Dinan TG (2012) Mind-altering microorganisms: the impact of the gut microbiota on brain and behaviour. Nat Rev Neurosci 13: 701-712.

9. Kelly JR (2016) Transferring the blues: Depression-associated gut microbiota induces neurobehavioural changes in the rat. J Psychiatr Res 82: 109-118. [Crossref]

10. Gupta A, Cifu AS, Khanna S (2018) Diagnosis and Treatment of Clostridium difficile Infection. JAMA 320: 1031-1032. [Crossref]

11. Fretheim H (2020) Fecal microbiota transplantation in systemic sclerosis: A doubleblind, placebo-controlled randomized pilot trial. PloS One 15: e0232739 [Crossref]

12. Holzapfel WH, Haberer P, Snel J, Schillinger U, Huis in't Veld, et al. (1998) Overview of gut flora and probiotics. Int J Food Microbiol 41: 85-101. [Crossref]

13. Qu H, Zhang Y, Chai H, Gao ZY, Shi DZ (2019) Effects of microbiota-driven therapy on inflammatory responses in elderly individuals: A systematic review and metaanalysis. PloS One 14: e0211233 [Crossref]

14. Karl JP (2017) Changes in intestinal microbiota composition and metabolism coincide with increased intestinal permeability in young adults under prolonged physiological stress. Am. J. Physiol. Gastrointest. Liver Physiol 312: G559-G571. [Crossref] 
15. Danping Zheng (2020) Interaction between microbiota and immunity in health and disease. Cell Research 30: 492-506.

16. Gomes-Neto JC, Round JL (2018) Gut microbiota: a new way to take your vitamins. Nature Reviews Gastroenterology \& Hepatology 15: 521-522.

17. Strandwitz P (2018) Neurotransmitter modulation by the gut microbiota. Brain Res 1693: 128-133. [Crossref]

18. Dang X, Xu M, Liu D, Zhou D, Yang W (2020) Assessing the efficacy and safety of fecal microbiota transplantation and probiotic VSL\#3 for active ulcerative colitis: A systematic review and meta-analysis. PloS One 15: e0228846. [Crossref]

19. Turnbaugh, P. J (2009) A core gut microbiome in obese and lean twins. Nature 457 480-484. [Crossref]

20. Qin J (2012) A metagenome-wide association study of gut microbiota in type 2 diabetes. Nature 490: 55-60.

21. Saurman V, Margolis KG, Luna RA (2020) Autism Spectrum Disorder as a Brain-GutMicrobiome Axis Disorder. Dig Dis Sci 65: 818-828. [Crossref]

22. Myers B (2019) The gut microbiome in psoriasis and psoriatic arthritis. Best Pract Res Clin Rheumatol 33: 101494.

23. Ticinesi A, Nouvenne A, Meschi T (2019) Gut microbiome and kidney stone disease: not just an Oxalobacter story. Kidney Int 96: 25-27. [Crossref]

24. Dhar D, Mohanty A (2020) Gut microbiota and Covid-19- possible link and implications. Virus Res 285: 198018. [Crossref]
25. Lawson CE (2019) Common principles and best practices for engineering microbiomes Nat Rev Microbiol 17: 725-741. [Crossref]

26. Olesen SW, Leier MM, Alm EJ, Kahn SA (2018) Searching for superstool: maximizing the therapeutic potential of FMT. Nat Rev Gastroenterol Hepatol 15: 387-388. [Crossref]

27. Cammarota, G. et al. International consensus conference on stool banking for faeca microbiota transplantation in clinical practice. Gut 68, 2111-2121 (2019). [Crossref]

28. De Angelis M (2020) Diet influences the functions of the human intestinal microbiome. Sci Rep 10: 4247. [Crossref]

29. Scheiman J (2019) Meta-omics analysis of elite athletes identifies a performance-enhancing microbe that functions via lactate metabolism. Nat Med 25: 1104-1109 [Crossref]

30. Dickson I (2017) Intestinal microbiota oscillations regulate host circadian physiology. Nat Rev Gastroenterol Hepatol 14: 67-67.

31. Taur Y (2018) Reconstitution of the gut microbiota of antibiotic-treated patients by autologous fecal microbiota transplant. Sci Transl Med 26: eaap9489. [Crossref]

32. Fong W, Li Q, Yu J (2020) Gut microbiota modulation: a novel strategy for prevention and treatment of colorectal cancer. Oncogene 39: 4925-4943.

33. Pérez-Matute P, Íñiguez M, de Toro M, Recio-Fernández E, Oteo JA (2020) Autologous fecal transplantation from a lean state potentiates caloric restriction effects on body weight and adiposity in obese mice. Sci Rep 10: 9388

34. Di Maira T, Berenguer M (2020) COVID-19 and liver transplantation. Nat Rev Gastroenterol Hepatol 1-3.

Copyright: (C2020 Herms JA. This is an open-access article distributed under the terms of the Creative Commons Attribution License, which permits unrestricted use, distribution, and reproduction in any medium, provided the original author and source are credited. 